\title{
POTENCIAL FITORREMEDIADOR DO “FEIJÃO-DE-PORCO” SUBMETIDO A DIFERENTES CONCENTRAÇÕES DE ESCÓRIA DE SIDERURGIA
}

F. K. D. OLIVEIRA ${ }^{1}$, A. A. L. SOUZA ${ }^{2}$
$\begin{gathered}\text { Universidade Federal do Sul e Sudeste do Pará }{ }^{1}, \text { Universidade Federal do Pará }^{2} \\ \text { kidelmar@unifesspa.edu.br }{ }^{1}\end{gathered}$
Submetido $25 / 11 / 2017$ - Aceito $17 / 09 / 2019$
DOI: $10.15628 /$ holos.2020.6609

\section{RESUMO}

O presente estudo utiliza o recurso de uma pesquisa experimental por meio da técnica de fitorremediação, com o uso da Canavalia ensiformis (feijão-de-porco) como fitorremediador de solos contaminados por escória de siderurgia. A análise foi feita em cinco tratamentos submetidos a diferentes doses do contaminante $(0,32$,

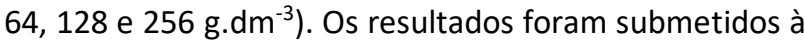
análise de variância e as médias comparadas pelo Teste de Tukey a $5 \%$. Concluiu-se que o padrão de crescimento do vegetal foi afetado pelo contaminante, sendo que o Tratamento 02 apresentou maior desenvolvimento do ramo e produção de fitomassa quando comparado aos demais, enquanto o Tratamento 04 obteve menor taxa de crescimento do ramo, seguido de menor produção de fitomassa se comparado aos demais testemunhos.

PALAVRAS-CHAVE: fitorremediação, canavalia ensiformis, metal pesado.

\section{PHYTOREMEDIATION POTENTIAL OF “FEIJÃO-DE-PORCO" SUBJECTED TO DIFFERENT CONCENTRATIONS OF STEEL SLAG}

\begin{abstract}
This study uses the experimental research by phytoremediation technique, with the use of Canavalia ensiformis as a soil phytoremediation contaminated by slag, the analysis was done in five treatments under different doses of the contaminant $(0,32,64,128$ and 256 grams). The results were submitted to analysis of variance and the means compared by $5 \%$ Tukey test. It
\end{abstract}

can be concluded that the plant growth pattern was affected by the contaminant and the treatment 02 showed further development of the branch and biomass production compared to the others, and the Treatment 04 had lower branch growth rate followed by lower production biomass compared to other witnesses.

KEYWORDS: phytoremediation, canavalia ensiformis, heavy metal. 


\section{INTRODUÇÃO}

A decrescente atividade siderúrgica no Brasil é uma importante produtora de diversos tipos de escória, produzindo mais de três milhões de toneladas por ano (PRADO et al., 2002), os quais, muitas vezes, são acumulados nos pátios das indústrias, gerando sérios problemas ambientais.

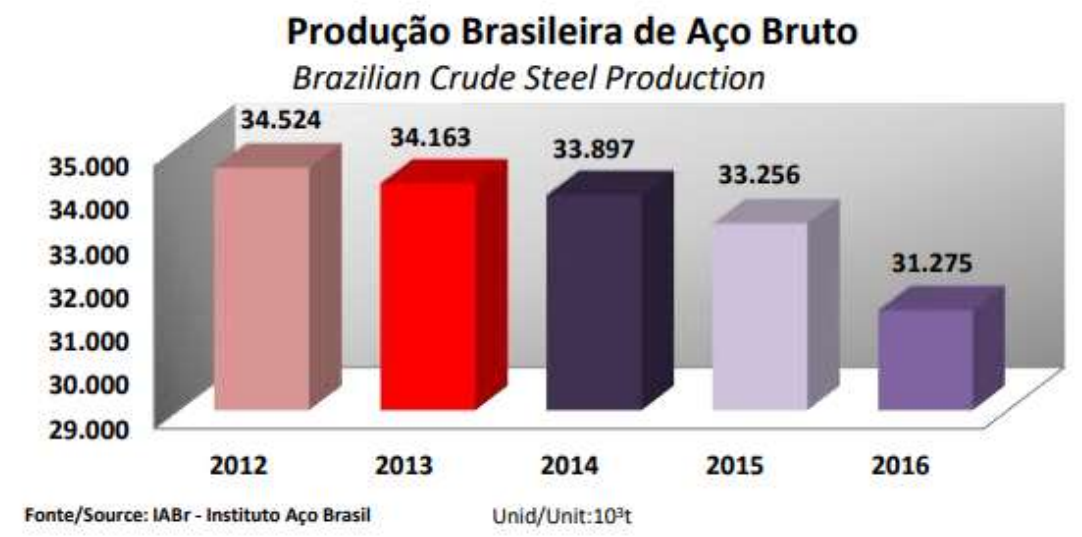

O Brasil é um dos maiores produtores de minério de Ferro e, consequentemente, de escória, subproduto no processo de produção do correspondente metal. Considerando a grande quantidade de escórias produzidas pelas siderúrgicas, esse material poderia ser aproveitado na agricultura, por exemplo, no entanto, sua maior quantidade é utilizada como aterro ou armazenada em locais impróprios (ADATIA \& BESFORD, 1986).

Segundo Wally (2005), uma das maiores dificuldades no uso de resíduos industriais, dentre eles as escórias de siderurgia, é a presença de contaminantes, que podem representar riscos de poluição ao ambiente e afetar negativamente a saúde humana. Entre os contaminantes mais comuns em resíduos siderúrgicos, encontram-se os metais pesados, que podem causar prejuízos às plantas e também trazer malefícios à saúde animal e humana. A contaminação por metais pesados é uma das mais preocupantes para o meio ambiente, pois esses, uma vez emitidos, não se transformam, permanecendo no ambiente durante centenas de anos e afetando a vegetação, as correntes de água, os animais e os seres humanos.

Uma das alternativas para a despoluição ambiental, principalmente de solos e águas, é a fitorremediação, técnica que utiliza sistemas vegetais para recuperar águas e solos contaminados por poluentes orgânicos ou inorgânicos. Diversos trabalhos relatam a utilização de leguminosas para esse fim, pois, além de essas espécies serem tolerantes a diversos herbicidas, podem ainda liberar exsudatos radiculares, que atuam ativando a microbiota do solo na decomposição dos compostos orgânicos aplicados (BELO, 2006).

Além disso, as leguminosas ainda apresentam outras características agronômicas, como produção de elevada biomassa fresca e seca, e fixação do nitrogênio atmosférico, contribuindo para maior ganho de matéria orgânica do solo, altamente desejável ao sistema produtivo (PIRES, 2003).

O objetivo principal do presente trabalho foi investigar o comportamento da espécie Canavalia ensiformis em diferentes concentrações de solo contaminado por escória de siderurgia. Como objetivos específicos, destacam-se: avaliar o crescimento dos ramos, o diâmetro do caule e 
o número de folhas em relação às diferentes concentrações utilizadas e determinar a extração de macro e micronutrientes pela planta com as diferentes concentrações de escória empregadas em cada tratamento.

\section{REVISÃO BIBLIOGRÁFICA}

Desde o início do século XX, as escórias siderúrgicas vêm sendo largamente utilizadas em vários países, gerando receitas e desempenhando importante papel como matéria prima para diversas aplicações, principalmente na construção civil e agricultura. A utilização da escória tem contribuído para a preservação dos recursos minerais não renováveis, por ser um produto que substitui os agregados naturais provenientes da mineração de granito, gnaisses, basaltos, calcários e outros materiais não metálicos (CGEE, 2008).

Por ser um resíduo sólido, é necessária, em alguns casos, a avaliação e a constatação de que seu uso não representa risco à saúde pública e ao meio ambiente. Em razão das restrições, parte da escória de aciaria não é comercializada, além disso, o setor de pavimentação rodoviária, maior mercado consumidor, apresenta caráter sazonal, o que contribui para o acúmulo de escória de aciaria nos pátios das siderúrgicas (CGEE, 2008).

É válido ressaltar que uma prévia caracterização química se faz necessária para avaliar a presença de metais pesados e outros elementos que possam causar impactos ambientais quando do seu uso (LOEMCO, 2003; TOURENQ et al., 2000).

Metais pesados são quimicamente e altamente reativos e bioacumulativos, ou seja, o organismo não é capaz de eliminá-los (OHLWEILER, 1971). Acredita-se que os metais sejam talvez os agentes tóxicos mais conhecidos pelo homem. De forma geral, as diferentes formas de vida são afetadas pela existência de metais, dependendo da forma química e da dose dos mesmos. Alguns metais se mostram essenciais para o desenvolvimento de vários tipos de organismos, desde bactérias até mesmo o ser humano, mas eles são requeridos em concentrações baixas, tendo em vista que podem danificar sistemas biológicos.

Os seres vivos necessitam de pequenas quantidades de alguns desses metais - incluindo cobalto, molibdênio, cobre, vanádio, manganês, estrôncio, e zinco - para a realização de funções vitais no organismo, porém elevados níveis desses elementos podem ser altamente tóxicos. Outros metais pesados, como o mercúrio, chumbo e cádmio, não possuem nenhuma função fisiológica conhecida nos organismos vivos, sendo considerados tóxicos em qualquer dose (BUSTAMANTE, 1993).

No que diz respeito às plantas, para crescer e completar o ciclo de vida, devem adquirir não apenas os macronutrientes nitrogênio, enxofre, potássio, fósforo, cálcio e magnésio, mas também micronutrientes essenciais, tais como ferro, zinco, manganês, níquel, cobre e molibdênio. Uma vez absorvidos, os metais tendem a acumular-se nas raízes, as quais são os primeiros órgãos vegetais afetados pela contaminação em situações de concentrações maiores do que o necessário, acarretando o escurecimento, engrossamento e inibição do crescimento radicular. Na parte aérea, os sintomas são a clorose; a perda de capacidade de produzir clorofila, similar à deficiência de ferro; aparecimento de manchas foliares e necrose, a morte dos tecidos da planta (LASAT, 2000).

No contexto de alternativas de recuperação de áreas degradadas, a biotecnologia oferece a fitorremediação como alternativa capaz de empregar sistemas vegetais fotossintetizantes e sua 
microbiota com o fim de desintoxicar ambientes. Incluem-se nesta desintoxicação compostos inorgânicos, elementos químicos radioativos, hidrocarbonetos derivados de petróleo, pesticidas e herbicidas, explosivos, solventes clorados e resíduos orgânicos industriais, entre outros (GLASS, 1998).

Para ser considerada boa remediadora, uma planta deve ser capaz de crescer na presença do contaminante e sobreviver sem diminuir sua taxa de crescimento, apesar da captura do contaminante e do seu acúmulo (PAJEVIC et al., 2009).

A fitorremediação é uma tecnologia emergente que é vantajosa, devido ao seu baixo custo e versatilidade. Não é uma solução para todos os problemas de resíduos perigosos, mas mostra um enorme potencial em diversas aplicações para o tratamento de metais e compostos orgânicos em locais onde a contaminação é superficial (SCHNOOR, 1997).

A técnica apresenta várias vantagens, porém o baixo custo é a principal, em relação às alternativas tradicionalmente utilizadas, envolvendo a remoção do solo para tratamento ex situ. Na maioria dos casos, os suprimentos e equipamentos utilizados no programa de fitorremediação são os mesmos empregados na agricultura. Logo, quando a fitorremediação é implantada em áreas agrícolas, o custo é ainda menor. É importante ressaltar que, apesar das substanciais vantagens, a técnica possui restrições como, por exemplo, a dependência de características inerentes ao clima e condições edáficas. Estas podem restringir o crescimento das plantas, ampliar o tempo requerido para obtenção de despoluição satisfatória, bem como influenciar na área superficial para aplicação da técnica, tanto em solos como em meios aquáticos, que requerem uma baixa profundidade (SANTOS 2008).

\section{MATERIAIS E MÉTODOS}

O experimento foi realizado no Campus II da Universidade Federal do Pará de Marabá, no município de Marabá-PA, no período de novembro de 2013 a fevereiro de 2014. O clima da região é o equatorial quente e úmido, apresentando temperaturas médias mensais entre $22,9^{\circ} \mathrm{C}$ e $32^{\circ} \mathrm{C}$, com média anual de $26^{\circ} \mathrm{C}$.

O delineamento experimental foi o inteiramente casualizado, com cinco tratamentos e cinco repetições por tratamento, totalizando 25 unidades experimentais. Cada unidade experimental foi constituída de dez vasos para mudas, nos quais foi realizado o semeio da Canavalia ensiformis, totalizando 250 unidades, utilizando-se solo enriquecido previamente com matéria orgânica.

As quantidades de escória misturadas ao solo de acordo com cada tratamento estão ilustradas na Tabela 1.

Tabela 1: Quantidade de escória por tratamento.

\begin{tabular}{c|c}
\hline Tratamento & $\begin{array}{c}\text { Quantidade de } \\
\text { escória }\left(\mathrm{g} \mathrm{dm}^{-3}\right)\end{array}$ \\
\hline T1 & 0 \\
T2 & 32 \\
\hline
\end{tabular}




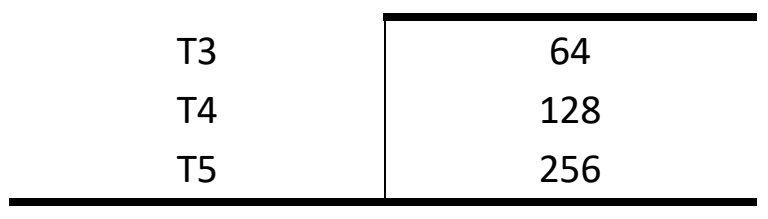

A escória siderúrgica utilizada no experimento foi cedida pela empresa Siderúrgica Norte Brasil S.A (Sinobras), que também forneceu a composição química da escória cedida (Tabela 2).

Tabela 2: Composição química da escória (\%).

\begin{tabular}{cccc}
\hline $\mathrm{CaO}$ & 48,337 & $\mathrm{~K}_{2} \mathrm{O}$ & 0,024 \\
$\mathrm{SiO}_{2}$ & 30,239 & $\mathrm{MnO}$ & 1,173 \\
$\mathrm{MgO}$ & 10,761 & $\mathrm{Na}_{2} \mathrm{O}$ & 0,005 \\
$\mathrm{P}_{2} \mathrm{O}_{5}$ & 0,013 & $\mathrm{~S}$ & 0,263 \\
$\mathrm{FeO}$ & 0,092 & $\mathrm{TiO}_{2}$ & 0,449 \\
$\mathrm{Al}_{2} \mathrm{O}_{3}$ & 5,693 & $\mathrm{~V}_{2} \mathrm{O}_{5}$ & 0,17 \\
$\mathrm{Cr}_{2} \mathrm{O}_{3}$ & 0,001 & Outros & 2,3 \\
$\mathrm{~F}$ & 0,484 & & \\
\hline
\end{tabular}

Para compor os vasos plásticos, juntamente com o solo, a escória passou por processos de homogeneização e quarteamento, depois foi separada em alíquotas de 32, 64, 128 e 256 gramas.

Na preparação de cada unidade experimental, misturou-se uma alíquota de escória ao solo e, então, a mistura foi colocada em um vaso plástico. Depois da preparação das 250 unidades experimentais, procedeu-se à irrigação para posterior semeio.

No Laboratório de Tratamento de Minérios da Faculdade de Engenharia de Minas e Meio Ambiente da Universidade Federal do Pará, foi realizada a análise granulométrica da escória, que está representada na Tabela 3.

Tabela 3: Distribuição granulométrica da escória.

\begin{tabular}{c|c|c|c|c}
\hline $\begin{array}{c}\text { Malha } \\
(\mu \mathrm{m})\end{array}$ & $\begin{array}{c}\text { Malha } \\
(\mathrm{mesh})\end{array}$ & \%Retida & $\begin{array}{c}\text { \%Retida } \\
\text { Acumulada }\end{array}$ & \%Passante \\
\hline 1400 & 12 & 52,95 & 52,95 & 47,05 \\
300 & 48 & 16,79 & 69,74 & 30,26 \\
150 & 100 & 6,14 & 75,88 & 24,12 \\
& Fundo & 24,12 & 100 & 0 \\
& Total & 100,00 & & \\
\hline
\end{tabular}

O experimento teve duração de 77 dias e, durante esse período, foram realizados alguns procedimentos como capina manual para retirada de plantas invasoras e irrigação, ministrada diariamente - com maior frequência nos primeiros dias após a semeadura e, em seguida, uma vez ao dia até o término de condução do experimento. 
Foram realizadas quatro coletas de dados ao longo dos 77 dias supracitados, sendo avaliadas três características: comprimento dos ramos, diâmetro do caule e número de folhas em cada amostra. Para medir o diâmetro e o comprimento das plantas foram utilizados paquímetro e trena graduada.

Ao final da quarta coleta, foi realizada a colheita das plantas para determinação da fitomassa verde da parte aérea e radicular. As plantas foram seccionadas na altura do colo e as raízes foram retiradas do solo e lavadas. Em seguida a parte aérea e radicular das plantas foi pesada em balança de precisão de Laboratório.

Para obtenção de massa seca da parte aérea e radicular das plantas, estas foram secas em forno elétrico a uma temperatura de 100 ㄷ C por um período de 72 horas e posteriormente pesadas.

Os dados coletados das características ao longo do experimento foram submetidos à análise da variância pelo programa estatístico ASSISTAT Versão 7.5 beta (SILVA, 2008).

\section{RESULTADOS E DISCUSSÕES}

Após as coletas dos dados ao longo de todo o experimento, uma parte do solo utilizado foi separada em amostras representativas, obedecendo aos padrões de homogeneização e quarteamento, e enviada ao laboratório para análise química. As Tabelas 04 e 05 mostram os resultados das análises correspondentes ao solo utilizado nos experimentos antes e depois de submetidos à contaminação pela escória siderúrgica, respectivamente.

Tabela 4: Análise química do solo utilizado no experimento livre de contaminação.

\begin{tabular}{l|l|c}
\hline \multirow{2}{*}{$\begin{array}{l}\text { PARÂMETRO } \\
\text { ANALISADO }\end{array}$} & \multirow{2}{*}{ UNIDADE } & $\begin{array}{c}\text { RESULTADO } \\
\text { DA ANÁLISE }\end{array}$ \\
\cline { 3 - 3 } & & Solo \\
\hline Fósforo & $\mathrm{mg} \cdot \mathrm{dm}^{-3}$ & 110 \\
Potássio & $\mathrm{mg} \cdot \mathrm{dm}^{-3}$ & 240 \\
Enxofre & $\mathrm{mg} \cdot \mathrm{dm}^{-3}$ & 9 \\
Cálcio & $\mathrm{cmolc} \cdot \mathrm{dm}^{-3}$ & 10,7 \\
Magnésio & $\mathrm{cmolc} \cdot \mathrm{dm}^{-3}$ & 0,7 \\
Alumínio & $\mathrm{cmolc} \cdot \mathrm{dm}^{-3}$ & 0 \\
H + Al & $\mathrm{cmolc} \cdot \mathrm{dm}^{-3}$ & 2,1 \\
pH em água & - & 6,4 \\
Matéria Orgânica & $\mathrm{dag} \cdot \mathrm{kg}^{-1}$ & 5,4 \\
Ferro & $\mathrm{mg} \cdot \mathrm{dm}^{-3}$ & 124 \\
Zinco & $\mathrm{mg} \cdot \mathrm{dm}^{-3}$ & 4,8 \\
Cobre & $\mathrm{mg} \cdot \mathrm{dm}^{-3}$ & 0,7 \\
Manganês & $\mathrm{mg} \cdot \mathrm{dm}^{-3}$ & 105 \\
Boro & $\mathrm{mg} \cdot \mathrm{dm}^{-3}$ & 0,33 \\
Sódio & $\mathrm{mg} \cdot \mathrm{dm}^{-3}$ & 110 \\
\hline
\end{tabular}


Tabela 5: Análise química do solo utilizado no experimento após divisão entre os tratamentos.

\begin{tabular}{l|l|c|c|c|c|c}
\hline PARÂMETRO & \multirow{2}{*}{ UNIDADE } & \multicolumn{6}{|c}{ RESULTADO DA ANÁLISE } \\
\cline { 3 - 7 } ANALISADO & & $\mathrm{T} 1$ & $\mathrm{~T} 2$ & $\mathrm{~T} 3$ & $\mathrm{~T} 4$ & $\mathrm{~T} 5$ \\
\hline Fósforo & $\mathrm{mg} \cdot \mathrm{dm}^{-3}$ & 53 & 46 & 40 & 21 & 5 \\
Potássio & $\mathrm{mg} \cdot \mathrm{dm}^{-3}$ & 190 & 290 & 380 & 520 & 660 \\
Enxofre & $\mathrm{mg} \cdot \mathrm{dm}^{-3}$ & 22 & 30 & 82 & 105 & 263 \\
Cálcio & $\mathrm{cmolc} \cdot \mathrm{dm}^{-3}$ & 3,8 & 6,3 & 5,9 & 5,9 & 5,7 \\
Magnésio & $\mathrm{cmolc} \cdot \mathrm{dm}^{-3}$ & 0,5 & 1,2 & 1,4 & 1,6 & 2,8 \\
Alumínio & $\mathrm{cmolc} \cdot \mathrm{dm}^{-3}$ & 0 & 0 & 0 & 0 & 0 \\
$\mathrm{H}+$ Al & $\mathrm{cmolc} \cdot \mathrm{dm}^{-3}$ & 0,9 & 0,9 & 1 & 0,8 & 0,7 \\
pH em água & - & 8 & 7,7 & 7,7 & 7,9 & 8 \\
Matéria Orgânica & $\mathrm{dag} \cdot \mathrm{kg}^{-1}$ & 5,1 & 5,1 & 5,1 & 4,7 & 4,4 \\
Ferro & $\mathrm{mg} \cdot \mathrm{dm}^{-3}$ & 151 & 138 & 111 & 86 & 40 \\
Zinco & $\mathrm{mg} \cdot \mathrm{dm}^{-3}$ & 95,7 & 819,3 & $2.053,2$ & $3.229,2$ & $5.740,9$ \\
Cobre & $\mathrm{mg} \cdot \mathrm{dm}^{-3}$ & 1,5 & 2,8 & 3,9 & 5 & 5 \\
Manganês & $\mathrm{mg} \cdot \mathrm{dm}^{-3}$ & 68 & 79 & 77 & 118 & 131 \\
Boro & $\mathrm{mg} \cdot \mathrm{dm}^{-3}$ & 0,41 & 0,67 & 0,93 & 2,01 & 2,44 \\
Sódio & $\mathrm{mg} \cdot \mathrm{dm}^{-3}$ & 101 & 170 & 320 & 410 & 610 \\
\hline
\end{tabular}

O parâmetro que diz respeito ao comprimento dos ramos foi coletado em quatro diferentes períodos do experimento, sendo mais bem exemplificado na Figura 1. Percebe-se uma relação entre os tratamentos 2 e 3, que obtiveram a maior taxa de crescimento em relação aos demais testemunhos, nos quais observa-se que o aumento gradativo da concentração de escória no solo provocou um aumento gradativo no padrão de crescimento da Canavalia ensiformis, porém com destaque nas fases mais próximas do desenvolvimento da espécie. Esse dado corrobora com Marques et al. (2000), no qual comentam que, em experimento realizado com espécies arbóreas cultivadas em solo contaminado por diferentes metais pesados, o crescimento em altura das espécies é influenciado pela contaminação do solo.

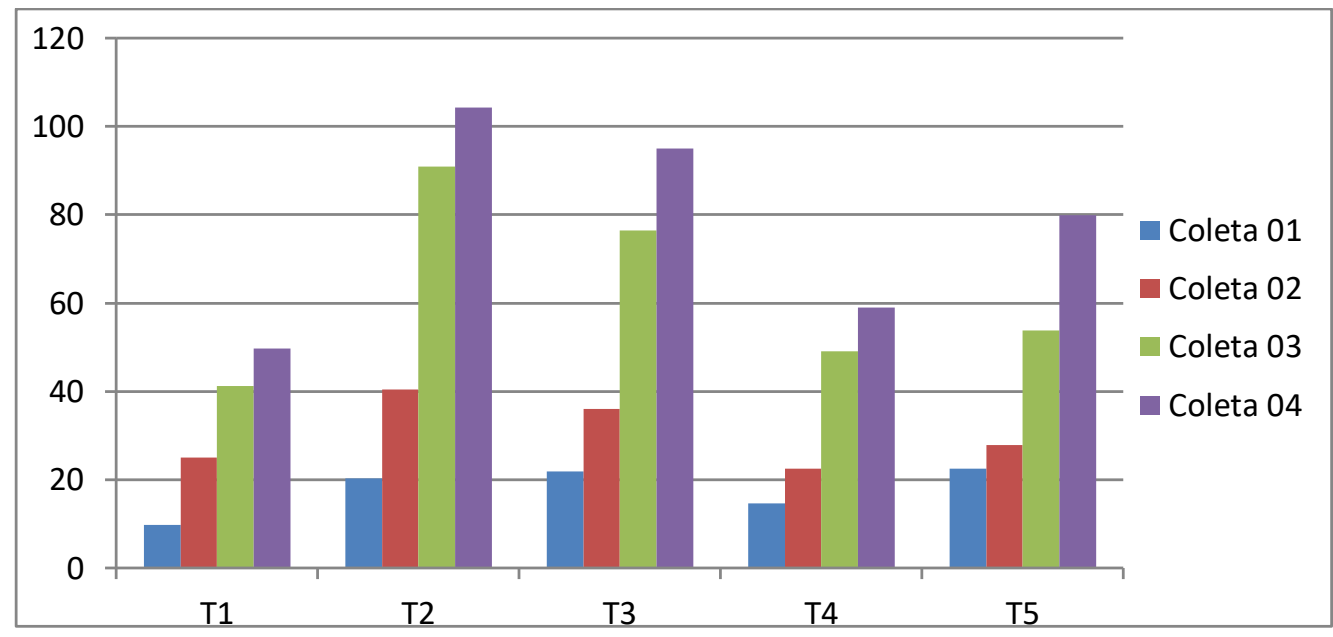

Figura 1: Crescimento dos ramos da Canavalia ensiformis durante o experimento.

Vale ressaltar que o Tratamento 1, embora isento de contaminação, apresentou um desenvolvimento menor do que os demais tratamentos, que possuíam solo contaminado pela 
escória, devido à amostra de solo do Tratamento 1 possuir menor disponibilidade de determinados macro e micronutrientes. Esse fato condiz com observação feita por Sobral e colaboradores (2011), que analisaram os efeitos da escória nos teores de nutrientes e melhorias nos atributos químicos do solo em estudo realizado com cana-de-açúcar.

A Tabela 6 ilustra os valores da produção de fitomassa da parte aérea e radicular do vegetal investigado.

Tabela 6: Fitomassa da parte radicular, aérea e total.

\begin{tabular}{l|c|c|c}
\hline Tratamentos & $\begin{array}{c}\text { Radicular } \\
(\mathrm{g})\end{array}$ & $\begin{array}{c}\text { Aérea } \\
(\mathrm{g})\end{array}$ & Total $(\mathrm{g})$ \\
\hline T1 & 478,6 & $1.673,0$ & $2.151,6$ \\
T2 & 732,1 & $3.390,0$ & $4.122,1$ \\
T3 & 644,2 & $2.398,2$ & $3.042,4$ \\
T4 & 418,6 & $1.251,5$ & $1.670,1$ \\
T5 & 592,3 & $1.381,0$ & $1.973,3$ \\
\hline
\end{tabular}

Baseado nos dados da Tabela 6, pode-se constatar que o Tratamento 2 apresentou maior taxa de produção de fitomassa $(4.122,1 \mathrm{~g})$ quando comparado aos demais tratamentos, tanto na parte radicular quanto aérea (732,1 g e $3.390 \mathrm{~g}$ respectivamente). Em contrapartida, o Tratamento 4 foi o que obteve os menores resultados de fitomassa também para ambas as partes do vegetal (418,6 g e 1.251,5 g). Esse fato, aliado aos dados descritos nas Tabelas 7 e 8, concordam com Greger (2003), que afirma que as plantas acumuladoras que possuem baixa produção de fitomassa tendem a apresentar alta acumulação de metais e que as plantas acumuladoras que produzem mais fitomassa tendem a acumular menos metal em seu sistema.

Nas Tabelas 7 e 8 constam a análise química dos tecidos vegetais para macro e micronutrientes da parte radicular e aérea da planta.

Tabela 7: Teor de macro e micronutrientes na parte radicular.

\begin{tabular}{|c|c|c|c|c|c|c|}
\hline \multirow{2}{*}{ Elementos } & \multirow{2}{*}{ Unidade } & \multicolumn{5}{|c|}{ Teor de Macronutrientes } \\
\hline & & T1 & $\mathrm{T} 2$ & T3 & T4 & T5 \\
\hline Nitrogênio & g. $\mathrm{kg}^{-1}$ & 13,51 & 14,14 & 16,17 & 10,43 & 9,03 \\
\hline Fósforo & g. $\mathrm{kg}^{-1}$ & 1,27 & 1,09 & 1,09 & 0,83 & 0,68 \\
\hline Potássio & g. $\mathrm{kg}^{-1}$ & 5,63 & 7,50 & 10,0 & 11,25 & 8,75 \\
\hline Cálcio & g. $\mathrm{kg}^{-1}$ & 10,98 & 8,86 & 7,74 & 7,92 & 6,68 \\
\hline Magnésio & g. $\mathrm{kg}^{-1}$ & 2,44 & 2,50 & 1,81 & 2,75 & 3,38 \\
\hline Enxofre & g. $\mathrm{kg}^{-1}$ & 1,05 & 1,51 & 1,93 & 2,99 & 2,39 \\
\hline \multirow{2}{*}{ Elementos } & \multirow{2}{*}{ Unidade } & \multicolumn{5}{|c|}{ Teor de Micronutrientes } \\
\hline & & $\mathrm{T} 1$ & $\mathrm{~T} 2$ & T3 & T4 & T5 \\
\hline Ferro & $\mathrm{mg} \cdot \mathrm{kg}^{-1}$ & 4.272 & 4.692 & 5.007 & 7.995 & 13.891 \\
\hline Zinco & $\mathrm{mg} \cdot \mathrm{kg}^{-1}$ & 119 & 887 & 1.505 & 2.955 & 4.589 \\
\hline Cobre & $\mathrm{mg} \cdot \mathrm{kg}^{-1}$ & 14 & 23 & 26 & 50 & 46 \\
\hline Manganês & $\mathrm{mg} \cdot \mathrm{kg}^{-1}$ & 173 & 222 & 240 & 238 & 505 \\
\hline Boro & mg.kg-1 & 18 & 25 & 27 & 33 & 39 \\
\hline
\end{tabular}


Tabela 8: Teor de macro e micronutrientes na parte aérea.

\begin{tabular}{|c|c|c|c|c|c|c|}
\hline \multirow{2}{*}{ Elementos } & \multirow{2}{*}{ Unidade } & \multicolumn{5}{|c|}{ Teor de Macronutrientes } \\
\hline & & $\mathrm{T} 1$ & $\mathrm{~T} 2$ & T3 & T4 & T5 \\
\hline Nitrogênio & g.kg-1 & 12,60 & 16,10 & 19,11 & 10,85 & 11,83 \\
\hline Fósforo & g. $\mathrm{kg}^{-1}$ & 0,83 & 1,16 & 1,56 & 1,20 & 0,96 \\
\hline Potássio & g. $\mathrm{kg}^{-1}$ & 10,0 & 13,75 & 21,25 & 23,75 & 21,25 \\
\hline Cálcio & g.kg-1 & 17,41 & 16,66 & 20,47 & 21,34 & 21,53 \\
\hline Magnésio & g. $\mathrm{kg}^{-1}$ & 1,94 & 1,38 & 2,13 & 2,69 & 3,0 \\
\hline Enxofre & g. $\mathrm{kg}^{-1}$ & 0,99 & 1,31 & 1,57 & 1,51 & 1,18 \\
\hline \multirow{2}{*}{ Elementos } & \multirow{2}{*}{ Unidade } & \multicolumn{5}{|c|}{ Teor de Micronutrientes } \\
\hline & & T1 & T2 & T3 & T4 & T5 \\
\hline Ferro & $\mathrm{mg} \cdot \mathrm{kg}^{-1}$ & 396 & 300 & 372 & 538 & 312 \\
\hline Zinco & $\mathrm{mg} \cdot \mathrm{kg}^{-1}$ & 203 & 79 & 195 & 276 & 173 \\
\hline Cobre & $\mathrm{mg} \cdot \mathrm{kg}^{-1}$ & 10 & 6 & 6 & 7 & 6 \\
\hline Manganês & $\mathrm{mg} \cdot \mathrm{kg}^{-1}$ & 21 & 29 & 57 & 52 & 51 \\
\hline Boro & $\mathrm{mg} \cdot \mathrm{kg}^{-1}$ & 19 & 31 & 57 & 71 & 92 \\
\hline
\end{tabular}

O Zn é um micronutriente essencial para os organismos, por ser um componente estrutural de muitas proteínas e, consequentemente, é um agente importante em diversas funções metabólicas nas plantas (CHANEY, 1993; LI et al., 2002). Em altas concentrações, no entanto, esse metal se torna potencialmente tóxico, podendo ocasionar diferentes danos à planta, entre eles a inibição do crescimento do vegetal (CARNEIRO et al., 2002), como provavelmente ocorreu com a C. ensiformis, uma vez que a parte aérea do Tratamento 4 apresentou maior porcentagem de $\mathrm{Zn}$ e, concomitantemente, menor taxa de crescimento do ramo.

Kabata-Pendias e Pendias (1985) consideram como tóxica a faixa de 100 a $400 \mathrm{mg} \cdot \mathrm{kg}^{-1} \mathrm{de}$ Zn. Assim, com exceção da parte aérea do Tratamento 2, todas as demais ocorrências do metal na C. ensiformis podem ser consideradas tóxicas.

Como foi observado, houve um considerável acúmulo de Fe na parte radicular e aérea da C. ensiformis, principalmente quando comparado aos demais macro e micronutrientes presentes no vegetal. O Fe é considerado micronutriente essencial às plantas, sendo um atuante direto em alguns mecanismos vitais como fotossíntese, fixação de $\mathrm{N}_{2}$ e processos iônicos (GUERINOT e YI, 1994).

Observa-se que a taxa de absorção de Fe na C. ensiformis foi significativa, o que consiste de um fato curioso, uma vez que o $\mathrm{pH}$ do solo usado no experimento se manteve numa faixa de neutro a ligeiramente básico e, segundo Camargo e Freitas (1985), o baixo pH propicia um aumento da disponibilidade de $\mathrm{Fe}^{2+}$ (forma absorvível pelas plantas) no solo. No entanto, Malavolta (1979) afirma que, quando o $\mathrm{pH}$ do solo está muito ácido ou alcalino, as espécies vegetais absorvem menos macro e micronutrientes, o que pode explicar a considerável eficácia da planta utilizada no experimento em absorver o Fe. 
Estudos de efeitos tóxicos do ferro em plantas tropicais são escassos e os sintomas de toxicidade ou agravantes físicos podem variar de planta para planta. Geralmente estão associados à capacidade do ferro em ser translocado para a parte aérea das plantas (FOY et al., 1978), o que compatibiliza com o estudo, já que, como foi constatado, o tratamento que obteve maior translocação de Fe para a parte aérea foi também o que demonstrou menor taxa de crescimento dos ramos e concomitante menor produção de fitomassa (Tratatamento 4), assim como aconteceu com o Zn.

O Cobre também apresentou valores peculiares na parte radicular do vegetal, uma vez que, com exceção do Tratamento 1, os demais apresentaram taxas acima das de referência para o metal (04 a 14 mg. $\mathrm{kg}^{-1}$ ), com ressalva especial para o Tratamento 4, que apresentou a maior taxa de concentração do elemento.

A mobilidade do cobre na fisiologia das plantas é limitada, devido a sua forte ligação com as paredes celulares, a translocação do cobre das raízes para as partes superiores é limitada, segundo relatam Wood et al. (1986), de forma que, no experimento realizado com a C. ensiformis, os resultados concordam com os autores supracitados.

Segundo Arduini et al. (1996), que verificaram a importância da raiz como órgão de reserva de cobre em espécies arbóreas, há uma forte relação entre o conteúdo de cobre na raiz destas espécies e a inibição do crescimento da parte aérea das mesmas, fato similar ao ocorrido com a $C$. ensiformis.

Malavolta, Vitti e Oliveira (1989) afirmam que, como efeitos tóxicos visíveis em plantas devido ao excesso de cobre em raízes, estão a diminuição no crescimento e ramificação e também a cessação do crescimento radicular, efeitos esses que explicam a baixa produção de fitomassa da C. ensiformis no Tratamento 4, uma vez que foi o tratamento que apresentou maior taxa de cobre na parte radicular $\left(50 \mathrm{mg} \cdot \mathrm{kg}^{-1}\right)$.

O experimento foi realizado em amostras de dimensões limitadas, por isso, apesar dos resultados, é importante notar que as plantas não tiveram condições de desenvolvimento pleno, logo podem não ter produzido uma quantidade de matéria seca máxima, o que pode também ter limitado, de certa forma, a capacidade da planta em acumular metais. Experimentos realizados no campo provavelmente obtêm resultados diferentes, pois a planta no vaso não somente explora um menor volume de solo, como também suas raízes ficam somente em contato com o solo contaminado. No campo, as raízes das plantas não se desenvolvem somente na camada contaminada pelos metais pesados, geralmente regiões mais superficiais, mas também exploram o solo mais profundamente, em áreas livres de contaminação, possibilitando à planta um desenvolvimento mais pleno apesar das condições de contaminação.

\section{CONCLUSÃO}

O aumento gradativo da concentração de escória como contaminante no solo provocou mudanças no padrão de crescimento da $C$. ensiformis e, concomitantemente, ocasionou aumento dos teores no solo de alguns elementos considerados nutrientes para as plantas, levando-se em conta a amostra controle (Tratamento 1) em comparação aos demais tratamentos. 
Estatisticamente, as três características estudadas (crescimento dos ramos, diâmetro do caule e número de folhas) apresentaram diferenças entre si em determinados aspectos e tratamentos, o que comprova as peculiaridades alcançadas em termos de desenvolvimento da planta no decorrer do experimento. Isso se deu principalmente no tocante ao Tratamento 2 e ao Tratamento 4, que diferiam estatisticamente das demais amostras em determinadas situações e, concomitantemente, foram os tratamentos que mais apresentaram peculiaridades no desenvolvimento do vegetal, uma vez que o Tratamento 2 obteve maior taxa de crescimento do ramo e maior produção de fitomassa, seguido de uma menor proporção de desenvolvimento do ramo e de produção de fitomassa pelo Tratamento 4.

A C. ensiformis apresentou real potencial de absorção de Fe e $\mathrm{Zn}$ no experimento para ambas as partes do vegetal (radicular e aérea), uma vez que as taxas dos dois metais no tecido da planta se apresentaram acima dos valores de referência, evidenciando uma capacidade promissora da planta em fitorremediar os citados nutrientes. No tocante ao $\mathrm{Cu}$, a espécie mostrou eficácia em fitorremediar o metal do solo e armazená-lo na parte radicular, o que se observou em menor proporção em relação ao Fe e Zn, já que a concentração do cobre, embora acima dos valores de referência, ficou no limiar aceitável em alguns dos tratamentos.

\section{REFERÊNCIAS}

ADATIA, M. H.; BESFORD, R. T. (1986). The effects of silicon on cucumber piant grown in recirculating nutrient solution. Annals of Botany. London, v. 58, p. $343-35$.

ANDRADE, C. M.; TAVARES, R. L.; MAHLER, C. F. (2007). Fitorremediação: o uso de plantas na melhoria da qualidade ambiental. São Paulo: Oficina de Textos, 176p.

ARDUINI, I.; GODBOLD, D. L.; ONNIS, A. (1996). Cadium and copper uptake and distribuition in Mediterranean tree seedlings. Physiol. Plant., v. 93, p. $111-117$.

BELO, A. F. (2006). Técnicas para fitorremediação de solo contaminado com herbicidas. 2006. Dissertação (Mestrado). Universidade Federal de Viçosa. Viçosa: UFV. Disponível em: http://serviços.capes.gov.br/capesdw/resumo.html?idtese=20061632 002017001P3. Acesso em 09. nov. 2016.

BUSTAMANTE, M. M. C. (1993). Biomonitoring of heavy metals using higher plants growing at former mining sites. Dissertation (Doctor de der Naturwissenschaf-ten) - Universität Trier, Tier.

CAMARGO C. E. O.; FREITAS J. G. (1985). Tolerância de cultivares de trigo a diferentes níveis de ferro em solução nutritiva. Bragantia, 44 p. $65-75$.

CARNEIRO M. A. C.; SIQUEIRA J. O.; MOREIRA F. M. S. (2002). Comportamento de espécies herbáceas em misturas de solo com diferentes graus de contaminação com metais pesados. Pesquisa Agropecuária Brasileira, 37: 1629 - 1638.

CENTRO DE GESTÃO E ESTUDOS ESTRATÉGICOS. (2008). Estudo Prospectivo do Setor Siderúrgico: Gestão de Coprodutos. Brasília, 28 p. (Nota Técnica). 
CHANEY, R. L. (1993). Zinc phytotoxicity. In, Robson, A. D. Zinc in soils and plants. Dordrecht, Kluwer Academic Publishers, pp. 135 - 150.

FOY, C. D.; CHANEY, R. L.; WHITE, M. C. (1978). The physiology of metal toxicity in plants. Annual Review of Plant Physiology, 29: p. $511-566$.

GLASS, D. J. (1998). The 1998 United States Market for Phytoremediation. D. Glass Associates, Needham, 139p.

GREGER, M. (2003). Phytoremediation - Does it work? In: INTERNATIONAL CONFERENCE ON THE BIOGEOCHEMESTRY OF TRACE ELEMENTS, 7., 2003, Uppsala-Sweden: SLU Service, p. $10-11$.

GUERINOT, M. A.; YI, Y. (1994). Iron: Nutritious, Noxious, and Not Readily Available. Plant Physiology. 104: p. $815-820$.

KABATA - PENDIAS, A.; PENDIAS, H. (1992). Trace elements in soils and plants. 2.ed. Boca Raton: CRC Press.

LASAT, M. M. (2000). Phytoextraction of metals from contaminated soil: a review of plant/soil/metal interaction and assessment of pertinente agronomic issues. Jornal of Hazardous Substance Research. Kansas State University, v. 2, s. 2 - 5.

LI X.; CHEN B.; FENG G.; CHRISTIE. P. (2002). Role of arbuscular mycorrhyzal fungi in alleviation of Zn phytotoxicity and mineral nutrition of host plants. In 17th WCSS, Thailand.

LOEMCO - Laboratório Oficial para ensayos de Materiales de Construcción [2003]. Áridos Especiales, In: Áridos - Manual de Prospeccion, Exploracion y Aplicaiones, Capítulo 19, p. 405 - 417, Escuela Tecnica Superior de Ingenieros de Minas de Madrid.

MALAVOLTA, E. (1979). ABC da Adubação. 4a edição. São Paulo SP, Editora Agronomia Ceres, 255 p.

MALAVOLTA, E. VITTI, G. C.; OLIVEIRA, S. A. (1989). Avaliação do estado nutricional das plantas. Princípios e aplicações. Piracicaba, SP: Associação Brasileira para Pesquisa da Potassa e do Fosfato. $201 \mathrm{p}$.

MARQUES, T. C. L. L. S. M.; MOREIRA, A. M. S.; SIQUEIRA, J. O. (2000). Crescimento e teor de metais de mudas de espécies arbóreas cultivadas em solo contaminado com metais pesados. Pesquisa Agropecuária Brasileira, v.35, n.1, p.121 - 132.

OHLWEILER, O. A. (1971). Química Inorgânica, Editora Edgar Blücher, São Paulo.

PAJEVIC, S.; BORISEV, M.; NIKOLIC, N.; KRISTIC, B.; PILIPOVIC, A.; \& ORLVIC, S. (2009). Phytoremediation capacity of poplar (Populus spp.) and willow (Salix spp.) clones in relation of photosynthesis. Archives of Biological Science Belgrade, 61(2), 239 - 247. doi: 10.2298/ABS0901239P.

PIRES, F. R. (2003). Seleção de espécies vegetais para fitorremediação de solos contaminados com tebuthiuron. Tese (Doutorado em Fitotecnia). Universidade Federal de Viçosa, Viçosa, 65 p. 
PRADO, R. M.; CORRÊA, M. C. M.; CINTRA, A. C. O.; NATALE, W.; SILVA, M. A. C. (2002). Liberação de micronutrientes de uma escória aplicada em um Argissolo Vermelho-Amarelo cultivado com mudas de goiabeira. (Psidiumguajava L.). Revista Brasileira de Fruticultura, v.24, p.536 542.

SANTOS, G. C. G.; RODELLA, A. A.; ABREU, C. A. (2008). Fitorremediação de solo contaminado por zinco, cobre, manganês, chumbo e boro por plantas de kenaf, mostarda, nabo e amaranto. Ciência Rural.

SCHNOOR, J. L. e DEE, P. E. (1997). Phytoremediation. Ground-Water Remediation Technologies Analysis Center. $37 \mathrm{p}$.

SILVA, F. DE A. DOS S. (2008). Programa estatístico ASSISTAT versão 7.5 (Beta). Campina Grande, Paraíba.

SOBRAL, M. F.; NASCIMENTO, C. W. A. do.; CUNHA, K. P. V. da. FERREIRA, H. A.; SILVA, A. J. (2011). Escória de siderurgia e seus efeitos nos teores de nutrientes e metais pesados em cana-deaçúcar. Revista Brasileira de Engenharia Agrícola e Ambiental, Campina Grande, v.15, n.8, p.867 - 872 .

WALLY, M. S. (2005). Resposta das Plantas e Modificações de Propriedades do Solo Pela Aplicação de Escória Básica de Aciaria. Dissertação (Mestrado). Faculdade de Agronomia, Universidade Federal do Rio Grande do Sul, Porto Alegre, 63 p.

WOOD, L. J.; MURRAY, B. J.; OKATAN, Y.; NOODÉN, L. D. (1986). Effect of petiole phloem distribution on starch and mineral distribution in senescing soybean leaves. American Journal of Botany, Bronx, v. 73, p. $1377-1383$. 